\title{
Effects of Cervical Joint Mobilization on the Forward Head Posture and Neck Disability Indexes.
}

\author{
Hyunju Oh, Byeongjun Hwang, Yoorim Choi
}

Department of Physical Therapy, Taegu Science University of Korea

\section{경부관절가동술이 두부전방자세와 경부장애지수에 미치는 영향 \\ 오현주, 황병준, 최유림 \\ 대구과학대학교 물리치료과}

\begin{abstract}
This paper tries to examine whether the application of joint mobilization to subjects who have the forward head posture due to malalignment in the cervical joint has influence on posture changes and functions in the cervical joint.

The subjects were 39 students from G University in Gyeongsangbuk-do. The cervical joint mobilization was applied to 20 subjects and not to 19 . The students with a cervical lordosis angle of $21^{\circ}$ or less, an anterior weight bearing (AWB) of $15 \mathrm{~mm}$ or greater, and a cervical extension ROM of $70^{\circ}$ or less in terms of radiography were selected as subjects under their voluntary agreement. The patients actively performed the joint mobilization slowly 8 times per session while therapists continuously applied sustained accessory glide to their painful joints 3 times per week for 4 weeks along with the cervical expansion and flexion in SNAGS among other Mulligan's (1995) techniques. The measurement was carried out in terms of radiographic inspection and neck disability indexes.

As a result of the experiment, it turned out that the subjects with the forward head posture had changes in the cervical AWB and ARA, the ranges of expansion and flexion, and the NDI(Neck Disability Index) after the intervention for the experimental group by applying cervical joint mobilization. There were no changes observed in the control group.

In conclusion, the application of joint mobilization turned out to have influence on the improvement of cervical joint postures, and craniocervical region functions.
\end{abstract}

Key Words: Joint mobilzation, Cervical posture, Mulligan Technic

\section{요 야}

경추관절의 부정렬로 인한 두부전방자세를 가진 대상자에게 관절가동술을 적용 후 경추관절의 자세변화와 기능에 영향을 미치는지 알아보고자 한다.

대상자들은 경상북도 $\mathrm{G}$ 대학 학생 39 명 중 경부관절가동술그룹 20 명, 가동술을 적용하지 않은 그룹 19 명을 나누어 
서 실시하였으며, 대상자들은 방사선 사진 촬영을 한 후 그 중 경추전만각(cervical lordosis angle)이 $21^{\circ}$ 이하이고, 머 리의 전방무게부하(anterior weight bearing, $\mathrm{AWB}$ )가 $15 \mathrm{~mm}$ 이상이며, 경추 신전 관절가동범위(extension $\mathrm{ROM}$ 가 $70^{\circ}$ 이하인 대학생을 선별하여 자발적 동의를 구하였다, Mulligan 기법(1995) 중 SNAGS로 경추 신전과 굴곡 운동을 주당 3 회, 4 주간 통증이 있는 관절을 치료사가 지속적인 종속활주운동(sustained accessory glide)을 적용하는 동안 환자가 능동적으로 관절운동을 각 회마다 천천히 8회 정도 적용하였다. 측정 방법은 방사선 검사와 경부장애지수를 통해 실시 하였다.

실험 결과 두부전방자세 대상자에게 경부관절가동술 적용 후 경부관절가동술군에서 경부의 $\mathrm{AWB}$ 와 $\mathrm{ARA}$, 굴곡신전 범위 변화, NDI에 대한 변화가 있음을 알 수 있었다. 대조군에서는 거의 변화가 없었다.

결론적으로 관절가동술 적용이 경부관절의 자세개선을 향상시키는데 영향을 미친 것으로 나타났고, 또한 두경부의 기능개선에서도 도움이 된 것으로 나타났다.

중심단어: 관절 놀이, 경부 자세, 멀리건 기술

\section{I. 서 론}

두부전방자세(Forward head posture, FHP)는 구조적 으로 머리의 중심선을 앞쪽과 위로 이동시키게 되어 목에서 지탱하는 머리의 무게가 증가하게 되고 이로 인해 머리뼈와 목 연결부의 전만 증가와 뒤통수 아래 근육, 목 근육, 어깨근육의 비정상적이고 지속적 근 수 축과 같은 상대적인 보상작용이 발생 되기도 한다. 이 는 두경부 연결부위의 변화를 유발하게 되는 것 ${ }^{[1]}$ 으로 올바르지 못한 자세에 의해 초래된 대표적인 자세라 고 할 수 있다.

두부전방자세를 취하게 되는 경우에는 해부학적인 연직선(plumb line)에 대해 두부가 전방에 위치하게 되 고, 이러한 자세에서 시선 보정을 위해 두부를 후방으 로 회전시키는 두개후방회전(posterior cranial rotation) 의 양상을 취하게 된다. 결과적으로 경부에서 하부근 의 신장이 초래되고, 장기적으로 지속될 경우 경추의 정상적인 전만의 상실이 나타나게 된다 ${ }^{[2][3]}$. 두부전방 자세는 머리에 의한 목의 역학적 스트레스를 만들어 내고 ${ }^{[4]}$, 이러한 스트레스로 인해 발생하게 되는 근육 불균형에 의해 어떤 근육은 억제, 약화되며 다른 근육 들은 긴장하게 되어 신장성을 소실하게 된다. 이러한 근육의 불균형은 두부전방자세, 굽은 어깨, 어깨상승, 견갑골의 비정상적인 자세를 보이게 되는 악순환을 가진다 ${ }^{[5]}$. 이로 인해 능형근(rhomboideus), 전거근 (serratus anterior), 하부 승모근(lower trapezius)과 같은 경부 하부근이 약해지고 그 반대 근육인 대-소흉근, 상 승모근, 견갑거근 등이 경직으로 딱딱해 지는 현상을 상위교차증후군(uppercrossed syndrome)이라고 한다 ${ }^{[6]}$.

두부전방자세를 치료하는 방법들 중 하나인 관절가 동술은 관절의 자유로운 가동성 유지 또는 정상회복 을 위해 관절면에 수동적 견인과 활주동작을 적용시 키는 치료기법 중 하나이다. 이 기법은 동통을 경감시 키거나 관절의 가동성을 증가시키기 위한 목적으로 사용한다.

관절가동술은 기능부전이 있는 척주에 대하여 가동 범위를 증가시키고 통증을 감소시키기 위하여 많이 사용되고 있으며 ${ }^{[7]}$, 경부통을 동반하여 가동범위에 제 한이 있는 환자에게 경부에 대한 도수치료 적용 시 능동적인 가동범위가 유의하게 증가하였다 ${ }^{[8]}$. 관절의 자유로운 동작을 허용하기 위해 신연(distraction), 활주 (gliding), 압박(compression), 구름(rolling), 회전(spinning) 등의 방법을 적절하게 적용하여 뺏뺏한 조직을 스트 레칭 시켜 관절가동범위를 증가시킬 수 있고 손상관 절의 정상적인 움직임을 촉진하여 영양공급을 원활히 함으로써 증상이 쉽게 악화되지 않게 하며, 관절움직 임을 통한 고유수용성 감각이 유해성자극을 주어 정 상 신경기능을 자극함으로써 통증인식을 억제할 수 있다 ${ }^{[9]}$.

관절가동술은 개념에 따라 여러 가지 기법들이 사 용되어지고 있다. 제한이나 통증이 있는 관절에 역학 적으로 조인트플레이(joint play)를 회복시키는 것 ${ }^{[10]}$ [11], 신전운동에 초점 둔 반복적인 운동을 이용한 자가 -치료운동이 있으며12]. 관절에 대한 율동적, 진동적 움 직임을 이용하여 관절가동범위의 증가를 위해 사용되 어지 기도하며 ${ }^{[13]}$, 중력과 체중이 실린 상태 즉, 병변 
이 발생한 환자의 기능적인 자세에서 치료사에 의해 움직임의 제한이 개선될 수 있는 가동술과 통증이 없 어진 상태에서의 환자의 능동적 움직임이 결합된 치 료방식 등 다양한 형태로 사용되어지지만 보편적으로 많이 사용하는 치료 기법 중에 하나이다 ${ }^{[14]}$. 관절가동 술이 치료사에 의해 가해지는 움직임으로 환자가 스 스로 그 움직임을 멈출 수 있을 만큼 느린 속도로 시 행하는 수동관절기법으로 동통을 경감시키고 관절의 가동성을 증가시키며 인체의 생리학적 운동이나 부수 적 운동을 회복시키는데 큰 효과가 있다고 하였다 ${ }^{[15]}$. 그 중 Mulligan 기법은 통증이 없는 범위에서 환자가 스스로 움직임기 때문에 근골격계의 통증과 기능장애 를 치료하는데 있어서 가동성과 결합된 능동적 운동 을 통한 새로운 접근을 시도하여 임상에서 많이 사용 되고 있다. ${ }^{[14]}$

이에 본 연구에서는 경추관절의 부정렬로 인한 두 부전방자세를 가진 대상자를 관절가동술을 적용하여 경추관절의 자세변화와 경부장애지수에 영향을 미치 는지 알아보고자 한다.

\section{II. 연구방법}

\section{1. 연구 대상}

본 연구의 대상자들은 경상북도 $\mathrm{G}$ 대학 학생들 중 방사선 사진 촬영을 한 후 그 중 경추전만각(cervical lordosis angle)이 $21^{\circ}$ 이하 이고 ${ }^{[16][17]}$, 머리의 전방무게부 하(anterior weight bearing, AWB)가 $15 \mathrm{~mm}$ 이상 이며, 경추 신전 관절가동범위(extension $\mathrm{ROM}$ )가 $70^{\circ}$ (Neuman)이하 인 두부전방자세를 가진 대학생을 선별하여 실험에 참가하기 전 연구 목적과 방법에 대하여 충분한 설명 을 듣고, 이에 자발적 동의를 한 후, 연구에 참여하였 다. 또한 연구윤리위원회 승인을 거쳤으며, 최근 통증의 경감을 위한 치료나 약물을 주기적으로 복용한 자, 신 경학적 문제가 있는 자는 제외시켰으며, 참여한 대상 자의 신체적 특성은 (Table 1)과 같다.
Table 1. General characteristics of each group (Mean \pm SD)

\begin{tabular}{ccc}
\hline & $J M(n=20)$ & Control $(n=19)$ \\
\hline (Male / Female) & $11 / 9$ & $9 / 10$ \\
\hline Age(years) & $21.35 \pm 3.65$ & $22.84 \pm 4.44$ \\
\hline Height $(\mathrm{cm})$ & $169.05 \pm 6.87$ & $167.58 \pm 8.70$ \\
\hline Body Weight $(\mathrm{kg})$ & $62.15 \pm 13.27$ & $59.47 \pm 11.42$ \\
\hline
\end{tabular}

\section{2. 측정 도구 및 방법}

\section{1 관절가동술}

Mulligan 기법 중 SNAGS로 경추 신전과 굴곡 운동 을 주당 3회, 4주간 실시하였다 ${ }^{[14]}$. 통증이 있는 관절을 치료사가 지속적인 종속활주운동(sustained accessory glide)을 적용하는 동안 환자가 능동적으로 관절운동을 하는 것으로 치료사는 대상자가 편안한 상태로 자세 를 취하고 각 회마다 천천히 8회 정도 적용하였다.

\section{1 .1 경추 신전을 위한 관절가동술}

SNAGS는 대상자를 의자에 앉힌 다음 치료사는 고 정된 관절의 위쪽 극돌기를 양쪽 엄지손가락을 이용 해 후관절(facet joint)의 관절면을 따라 밀어 올리고, 환 자는 천천히 신전한다. 이때 활주(gliding)는 대상자의 목이 중립위치로 돌아 올 때 까지 유지되어야 한다. 이러한 방법을 경추의 아래쪽 관절에서부터 위쪽관절 로 적용한다 ${ }^{[14]}$.
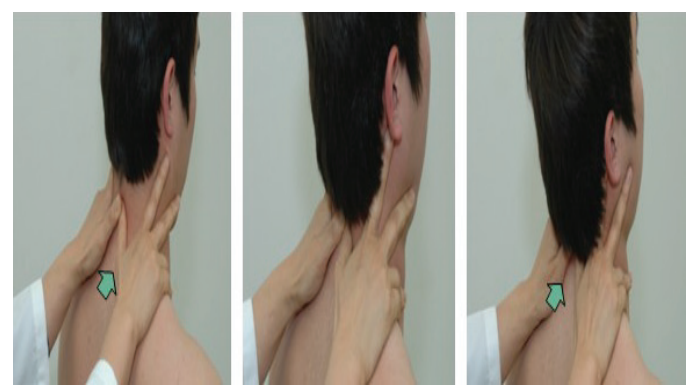

Fig. 2. Joint mobilization for cervical extension. 
(2) 경추 굴곡을 위한 관절가동술

경추 굴곡을 위한 기법으로 SNAGS와 주먹견인(fist traction)을 받는다. 굴곡을 위한 SNAGS는 대상자를 의 자에 앉힌 다음 치료사는 대상자의 뒤에 서서 fix된 관 절의 위쪽 극돌기를 양쪽 엄지손가락을 이용해 후관 절(facet joint)의 관절면을 따라 밀어 올리고, 환자는 목 을 굴곡한다. 이러한 방법을 경추의 아래쪽 관절에서 부터 위쪽관절로 적용하고 주먹견인 또한 대상자를 의자에 앉힌 다음 치료사는 대상자의 뒤에 서서 한손 으로 주먹을 만들어 원모양으로 형성된 시지와 엄지 로 대상자의 턱을 받치고, 새끼손가락을 흥골 상단에 놓은 다음, 대상자에게 스스로 한손으로 후두골 아래 부분을 잡고 머리를 전하방으로 당기라고 한다.
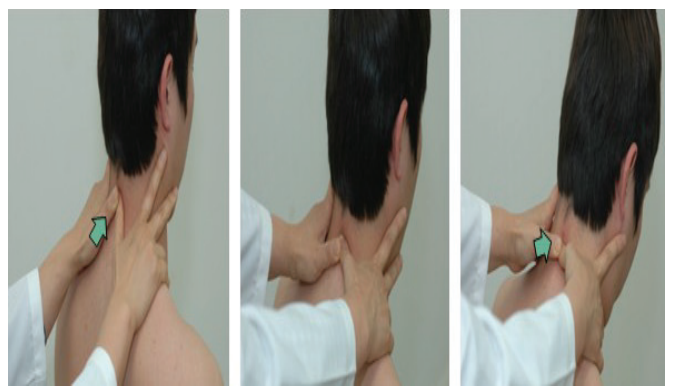

Fig. 3. Joint mobilization for cervical extension.

\section{3. 측정 방법}

\section{1 방사선 검사}

실제적인 경추정렬의 변화는 디지털 카메라로는 확 정 할 수 없기 때문에 X-ray촬영으로 경추의 정렬상태 를 확인하였다. 목의 전만 정도를 측정하기 위하여 절 대회전각(absolute rotation angle, ARA), 두부전방자세 (forward head posture)를 알아보기 위해 전방무게부하 (anterior weight bearing: $\mathrm{AWB})^{[18]}$, 목의 굴곡과 신전 각 도를 알아보기 위하서 굴곡과 신전의 범위(range of flexion and extension motions, RFEM)를 관찰하였다. 방사선 촬영은 대상자의 비골근부(root of nose)와 외후 두골 돌출부(external occipital protuberance)가 수평선을 이룬 상태에서 선체로 눈을 감고 경부, 견부 그리고 상완부의 근육들을 최대한 이완시킨 상태에서 가능한
편안하고 자연스런 자세를 취하도록 한 후 X-ray (DLD-150 RK, Dong-A company, 한국)로 $1 \mathrm{~m}$ 거리에서 동일한 방사선사가 촬영을 하고 필름은 $14 \times 14$ inch를 사용하였다.

절대회전각(absolute rotation angle: $\mathrm{ARA}$ )은 $\mathrm{C} 2$ 의 추 체 후면 연장선과 $\mathrm{C} 7$ 의 추제 후면의 연장선이 만나 이 루는 각도이고, 머리의 전방무게부하(anterior weight bearing: $\mathrm{AWB})$ 는 $\mathrm{C} 7$ 의 추체 후하방 모서리 부위에서 수직으로 선을 긋고, $\mathrm{C} 2$ 의 추체 후상방 모서리 부위에 서 수평거리이다. 굴곡과 신전의 범위(range of flexion and extension motions, RFEM)은 경추를 굴곡하였을 때 $\mathrm{C} 2$ 의 추체 하면 연장선과 $\mathrm{C} 7$ 의 추제 상면의 연장선이 만나 이루는 각도와 경추를 신전하였을 때 $\mathrm{C} 2$ 의 추체 하면 연장선과 $\mathrm{C} 7$ 의 추제 상면의 연장선이 만나 이루 는 각도를 합한 각도이다.

경추전만각(cervical lordosis angle)이 $21^{\circ}$ 이하이고, 머리의 전방무게부하(anterior weight bearing, $\mathrm{AWB}$ )가 $15 \mathrm{~mm}$ 이상이며 ${ }^{[19][20]}$, 신전관절가동범위(extension ROM)

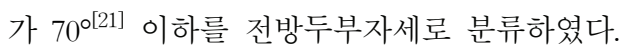

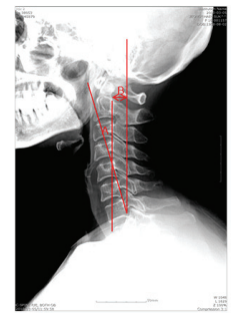

$\mathrm{ARA}, \mathrm{AWB}$

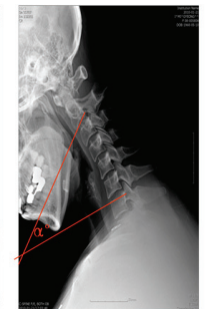

Flexion

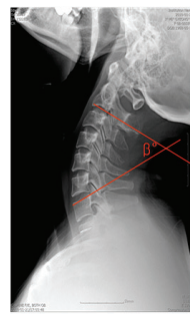

Extension
Fig. 4. Measuring the $\operatorname{ARA}(A), \operatorname{AWB}(B)$, flexion $\left(a^{\circ}\right)$, and extension $\left(\beta^{\circ}\right)$ by using diagnostic radiation equipment.

\section{2 경부장애지수(Neck Disability Index, NDI)}

경부장애지수 설문지는 총 10 문항으로 대상자의 경 부통과 기능장애를 측정하도록 고안되었다. 통증강도, 일상생활, 들어올리기, 읽기, 두통, 집중도, 일, 운전, 수 면, 여가생활의 10 개 항목에 대하여 각각 6 개의 항목 중 하나를 선택하게 되어 있다(0-5점). 점수는 각 항목 의 합계로 점수가 높을수록 경부이상과 관련된 기능 장애가 큰 것을 나타낸다. 점수의 범위는 0-50점이고 0-4점은 장애 없음(no disability), 5-14점은 약간의 장애 
(mild disability), 15-24점은 중등도의 장애(moderate disability), 25-34점은 심한 장애(severe disability), 35점 이 상은 완전한 장애(complete disability)로 제시하였다 ${ }^{[22]}$.

\section{4. 측정 방법}

자료 분석은 SPSS 14.0 for window를 이용하여 관절 가동술적용군과 대조군의 중재 전, 후 자세 평가 변화 를 비교하여 두부전방자세에 미치는 영향을 비교 분 석하였다.

통계 분석은 종속 변수인 자세와 기능장애지수의 특성에 대한 전, 후 차이 비교를 위해 대응표본 t-검정 (paired t-test)을, 두 집단간 차이비교를 위해 독립표본 T검정(independent t-test)을 실시하고, 각 군 간의 일반 적인 특성에 대한 검정을 위해 평균과 표준편차를 구 하였다. 통계학적 유의수준을 검증하기 위한 유의수준 은 0.05 로 설정하였다.

\section{V. 결 과}

\section{1. 경부 자세 변화}

\section{1 전후 전방체중지지(AWB) 비교}

중재 전 각 군 간에 유의한 차이는 보이지 않았으나 (p>.05), 중재 후 군 간 $\mathrm{AWB}$ 는 통계적인 유의한 차이 를 보였다(p<.05).

각 군의 중재 전과 후의 $\mathrm{AWB}$ 차이를 비교한 결과 관절가동술군은 중재 후가 중재 전에 비해 통계적으 로 유의하게 나타났으나 $(\mathrm{p}<.05)$, 대조군에서는 통계적 으로 유의한 차이를 보이지 않았다(p>.05)(Table 2).

Table 2. Comparison of AWB between pre and post test

\begin{tabular}{cccc} 
& & & (unit : mm) \\
\hline & Joint mobilization & Control & $t$ \\
\hline Pre & $22.55 \pm 4.14$ & $22.00 \pm 4.64$ & .39 \\
\hline Post & $18.60 \pm 3.82$ & $23.45 \pm 6.43$ & $2.89 \star$ \\
\hline $\mathrm{t}$ & $3.61 *$ & .86 & \\
\hline & & & $* \mathrm{p}<.05$
\end{tabular}

AWB: anterior weight bearing

\section{2 전후 완전 회전 각도(ARA) 비교}

중재 전 각 군 간에 유의한 차이는 보이지 않았으나 (p>.05), 중재 후 군 간 ARA는 통계적인 유의한 차이 를 보였다( $\mathrm{p}<.05)$.

각 군의 중재 전과 후의 ARA 비교 결과 관절가동 술군은 중재 후가 중재 전에 비해 통계적으로 유의하 게 나타났으나 $(\mathrm{p}<.05)$, 대조군에서는 통계적으로 유의 한 차이는 나타나지 않았다( $\mathrm{p}>$.05)(Table 3).

Table 3. Comparison of ARA between pre and post test

\begin{tabular}{cccc} 
& & & (unit : ${ }^{\circ}$ ) \\
\hline & Joint mobilization & Control & $\mathrm{t}$ \\
\hline Pre & $11.65 \pm 4.72$ & $10.63 \pm 3.58$ & .801 \\
\hline Post & $15.25 \pm 3.24$ & $11.68 \pm 3.51$ & $3.69 \star$ \\
\hline $\mathrm{t}$ & $3.04 *$ & 1.38 & \\
\hline & & & $* \mathrm{p}<.05$
\end{tabular}

ARA: absolute rotation angle

\section{3 경추 굴곡 각도 전후 비교}

중재 전 각 군 간 경추의 굴곡 각도에서 유의한 차 이를 보이지 않았으나(p>.05), 중재 후 군 간 경추의 굴곡 각도는 통계적으로 유의한 차이를 보였다(p $<.05)$.

각 군의 중재 전과 후의 경추 굴곡 각도 비교 결과 관절가동술군은 중재 후가 중재 전에 비해 통계적으 로 유의하게 나타났으나(p<.05), 대조군에서는 통계적 으로 유의한 차이는 나타나지 않았다( $\mathrm{p}>$.05)(Table 4).

Table 4. Comparison of flexion angle between pre and post test

\begin{tabular}{cccc}
\hline & Joint mobilization & Control & $\mathrm{t}$ \\
\hline Pre & $17.55 \pm 9.68$ & $18.08 \pm 7.78$ & .41 \\
\hline Post & $23.38 \pm 6.39$ & $18.58 \pm 4.93$ & $2.38 *$ \\
\hline $\mathrm{t}$ & $3.93 *$ & .19 & \\
\hline & & & $* \mathrm{p}<.05$ \\
\hline
\end{tabular}

\section{4 경추 신전 각도 전후 비교}

중재 전 각 군 간 경추의 신전 각도에서 유의한 차 이를 보이지 않았으나(p>.05), 중재 후 군 간 경추 신 
전 각도는 통계적으로 유의한 차이를 보였다 $(\mathrm{p}<.05)$.

각 군의 중재 전과 후의 경추 신전 각도 비교 결과 관절가동술군은 중재 후가 중재 전에 비해 통계적으 로 유의하게 나타났으나 $(\mathrm{p}<.05)$, 대조군에서는 통계적 으로 유의한 차이는 나타나지 않았다(p>.05)(Table 5).

Table 5. Comparison of extension angle between pre and post test (unit : ${ }^{\circ}$ )

\begin{tabular}{cccc}
\hline & Joint mobilization & Control & $\mathrm{t}$ \\
\hline Pre & $50.68 \pm 11.07$ & $51.34 \pm 7.85$ & .09 \\
\hline Post & $57.38 \pm 7.18$ & $50.76 \pm 6.77$ & $3.00 *$ \\
\hline & $2.89 *$ & .06 & \\
\hline & & $* 0<.05$
\end{tabular}

\section{5 경추 굴곡신전 각도(RFEM) 전후 비교}

중재 전 각 군 간 경추의 굴곡신전 각에서 유의한 차이를 보이지 않았으나(p>.05), 중재 후 군 간 경추 신전 각도는 통계적으로 유의한 차이를 보였다 $(\mathrm{p}$ $<.05)$.

각 군의 중재 전과 후의 경추 굴곡신전 각도를 비교 한 결과 관절가동술군에서는 중재 후가 중재 전에 비 해 통계적으로 유의하게 나타났으나 $(\mathrm{p}<.05)$, 대조군에 서는 통계적으로 유의한 차이는 나타나지 않았다 (p>.05) (Table 6).

Table 6. Comparison of RFEM between pre and post test

\begin{tabular}{cccc} 
& & & (unit : ${ }^{\circ}$ ) \\
\hline & Joint mobilization & Control & $\mathrm{t}$ \\
\hline Pre & $68.23 \pm 11.04$ & $69.42 \pm 9.76$ & .45 \\
\hline Post & $80.75 \pm 9.64$ & $69.34 \pm 7.52$ & $3.97 \star$ \\
\hline $\mathrm{t}$ & $5.91 \star$ & .05 & \\
\hline & & & $* 0<.05$
\end{tabular}

RFEM: range of flexion and extension motion

\section{6. 중재에 따른 군 간 경부장애지수(NDI) 비교}

중재 전 각 군에서 경부장애지수 점수는 유의한 차이를 보이지 않았으나(p>.05), 중재 후 군 간 경부장 애지수 점수는 통계적으로 유의한 차이를 보였다(p $<.05)$.

각 군의 중재 전과 후의 경부장애지수 점수를 비교
한 결과 관절가동술군에서는 중재 후가 중재 전에 비 해 통계적으로 유의하게 나타났으나 $(\mathrm{p}<.05)$, 대조군에 서는 통계적으로 유의한 차이는 나타나지 않았다 (p>.05) (Table 7).

Table 7. Comparison of NDI between pre and post test

(unit : score)

\begin{tabular}{cccc}
\hline & Joint mobilization & Control & $\mathrm{t}$ \\
\hline Pre & $7.40 \pm 2.06$ & $7.53 \pm 1.78$ & .08 \\
\hline Post & $4.55 \pm 1.93$ & $7.68 \pm 1.92$ & $5.15 *$ \\
\hline $\mathrm{t}$ & $7.52 *$ & .39 & \\
\hline & & & $* 0<.05$
\end{tabular}

NDI: neck pain and disability index

\section{$\mathrm{V}$. 고 찰}

최근 현대인들은 켬퓨터 관련 기기 및 휴대용 미디 어 기기의 이용 급증으로 잘못된 생활습관이나 반복 적인 컴퓨터 단순 작업 등에 기인된 근육 긴장과 이로 인한 신경 압박으로 경부의 통증이 증가하고 있다 ${ }^{[23]}$.

환경과 자세의 위치에 따라 변화되는 두경부의 역 학적 기능부전은 자세유지의 불균형을 초래하고 관절 가동범위의 제한과 통증을 동반하게 된다 ${ }^{[24]}$.

본 연구는 두부전방자세가 있는 대학생에게 관절가 동술 적용 후 경부관절의 기능적인 역학적 변화가 있 는지를 알아보기 위해 방사선 검사(AWB, ARA, $\mathrm{RFEM})$, 와 경부장애지수(NDI)를 통해 자세변화와 기 능 변화를 비교 분석하였다.

본 연구에서는 중재에 따른 자세변화에서 $\mathrm{AWB}$ 는 관절가동술군에서 중재 후 유의하게 감소하였으며, 대 조군에서는 유의한 감소를 보이지 않았다. $\mathrm{ARA}$ 는 관 절가동술군에서 중재 후 유의하게 증하였으며, 대조군 에서는 유의한 증가를 보이지 않았다. 굴곡신전각에서 는 관절가동술군에서 중재 후 유의하게 증가하였으며, 대조군에서는 유의한 증가를 보이지 않았다. VDT작업 자의 경부 관절가동범위의 변화를 보면 가동운동군에 서 모든 움직임의 가동범위가 증가하였으며 이 중 굴 곡신전운동이 통계학적으로 유의한 증가를 나타냈다 고 하였다 ${ }^{[25]}$. 능동운동과 관절가동운동의 결과로 통증 과 관절가동범위의 변화가 나타났다고 하였으며 ${ }^{[26]}$, 경 추기능부전이 있는 환자를 대상으로 관절가동운동을 
적용하여 경부가동범위를 확인한 결과 유의하게 증가 되었음을 보고 하였다 ${ }^{[27]}$. 그 외에도 선행 연구에서 실 험 방법에 조금의 차이는 있지만 관절가동운동이 경 추관절가동범위 증가에 효과적이라고 보고하였다리. 이는 본 연구와 유사한 결과를 나타내었으며, 본 연 구에서는 관절가동술의 미끄러짐(gliding) 견인(traction) 등을 포함한 다양한 치료기법의 적용을 통해 관절가 동범위가 증가를 가져 온다. 이것은 결국 칼텐본-에비 엔즈컨셉(Kaltenborn-Evienth Concept)에서 분류하는 등 급1,2,3(Grade1,2.3)에서 각 등급에 따라 통증조절과 관 절의 신장을 일으킬 수 있음 알 수 있는데 ${ }^{[29]}$ 관절가동 술의 적용을 통해 통증이 사라지고 관절의 움직임이 기능적으로 잘 움직일 수 있었으며 이는 목의 전만이 회복되고 전방체중지지(AWB)가 줄어들었을 것으로 사료된다. 또한 관절가동범위의 증가는 곧 목의 완전 회전각(ARA)의 증가와 굴곡 신전각에서도 증가를 가 져왔을 것으로 여겨진다.

한편 경부장애지수에서 급성 편타성과 연관된 경부 통증환자에게 운동적용 후 ${ }^{[30]}$, 만성경부통증 환자에게 운동 중재 후 경부장애지수가 감소하였다고 하였다리] 이는 경부장애지수에 포함된 항목인 통증과 움직임의 향상을 통해 환자의 일상생활에서의 기능적인 활동 즉 목욕하기, 물건들어올리기, 집중력, 운전 등 또한 많은 향상을 가져왔을 것으로 사료된다. 이것은 경부 자세 향상에 따른 목 주변 근육의 스트레스가 감소되 면서 경부장애지수 또한 감소시킨 것으로 생각되어진 다.

\section{$\mathrm{V}$. 결 론}

본 연구는 목 주변 근육의 위축과 경추부관절 부정 렬로 인한 두부전방자세에 관절가동술 적용 후 자세 의 변화에 영향을 미치는지에 대해 알아보고자 하였 다.

두부전방자세 대상자에게 경부관절가동술과 대조군 에서 경부관절가동술군에서 중재 후 경부의 $\mathrm{AWB}$ 와 $\mathrm{ARA}$, 굴곡신전범위 변화, NDI에 대한 변화가 있음을 알 수 있었다. 대조군에서는 경부자세와 $\mathrm{NDI}$ 에 대한 변화가 없었다. 이는 관절가동술 중재를 통해 본 연구 의 결과에서 두부전방자세에 관절가동술 적용이 경부
관절의 자세개선을 향상시키는데 영향을 미친 것으로 나타났고, 이와 같은 결과를 통해 물리치료에서 사용 되어지고 있는 경부관절가동술이 관절가동범위 증가 등이 삶의 질 뿐 만 두경부의 기능 향상 에도 매우 효과적인 것으로 나타났다. 향 후 연구에서 다양한 방 법과 대상자를 확대하여 지속적인 연구가 이루어졌으 면 한다.

\section{참고문헌}

[1] Harrison D.E., Harrisson D.D., Bets J.T., "Increasing the cervical lordosis with chiropractic biophysics seated combined extension-compression and transverse load cervical traction with cervical manipulation: nonrandomized clinical control trial", JMPT, Vol. 26, No.3, pp. 139-151, 2003.

[2] Kraus SL. "TMJ disorders management of the craniomandibualr complex". 2nd ed., New York: Churchill Livingstone, 1994.

[3] Sahrmann, S. A. "Diagonsis and treatment of movement impairment syndromes", Philadelpia: Mosby, 2001.

[4] Waris., "Scandinavian Journal of work, Environment and Health", Occupational cervicobrachial syndromes, Vol. 5, No.3, pp. 3-14, 1980.

[5] Janda V., "Rehabilitation of the spine", Baltimore: Williams \& Wilkins, 1996.

[6] Janda V. "Muscles and Motor Control in Cervicogenic Disorders: Assessment and Management", In Grant, R., Physical Therapy of the Cervical and Thoracic Spine, New York: Churchill Livingstone, 1994.

[7] Mennell J.M., "The Validation of the diagnosis 'Joint dysfunction' in the synovial joint of the cervical spine", JMPT, Vol. 13, pp. 7-12, 1990.

[8] Whittingham W., Nilsson N., "Active range of motion in the cervical spine increses after spinal manipulation(Toggle Recoil)", JMPT, Vol. 24, pp. 552-555, 2001.

[9] Godges J.J., Mattson-Bell M., Thorpe D., Shah D., "The immediate effects of soft tissue mobilization with proprioceptive neuromuscular facilitation on glenohumeral external rotation and over headreach". JOSPT, Vol. 33. No.12, pp. 713-718, 2003.

[10] Kaltenborn F.M., "The spine: basic and mobilization techniques. Oslo: Olaf Noris Bikhandel", 1993.

[11] Chio WS, Park JH, Jung BJ et al. "A Study on shoulder joint motions in the caudal gliding of Kaltenborn-Evjenth", JKSR, Vol. 6, No. 5, pp. 427-433, 2012. 
[12] Mckenzie R.A., "Treat Your Own Neck. New Zealand: Spinal pubilcations", 1983.

[13] "Maitland GD, The treatment of joint by passive movement". AJPT, 20, pp129-135. 1986.

[14] Mulligan B.R,. "Manual therapy: NAGS, SNAGS, MWMS etc. OPT", 1995

[15] Kinser C., Colby L.A., "Theraputic Exercise Foundations and techniques", 5th ed., Philadelpia: F.A Davis. 2007.

[16] Gore D., Sepic S., Gardner G., "Roentgenographic findings of the cervical spine in asymptomatic people". Spine, Vol. 11, pp. 521-524, 1986.

[17] Owens E., Hoiris K., "Cervical curvature assessment using digitized radiographic analysis". JCR, Vol. 4, pp. 47-62, 1990.

[18] Oakley P.A., Harrison D.D., "Harrison DE. Evidence-based protocol for structural rehabilitation of the spine and posture: review of clinical biomechanics of posture $(\mathrm{CBP} \AA)$ publications", JCCA, Vol. 49, No. 4, pp. 270-296, 2005.

[19] Harrison D.E., Harrison D.D., Calliet R., Troyanorich S.J., Jank T.J., Hollad B., "Cobb method or harrison posterior tangent method: which to choose for lateral cervical radiographic analysis", Spine, Vol. 25, No. 16, pp. 2072-2078, 2000.

[20] Hermann K.M., Reese C.S., "Relationships among selected measures of impairment. funtional limitation and disability in patients with cervical spine disorders", PT, Vol. 81, pp. 903-914, 2001.

[21] Neumann D.A., "Axial skeleton: Muscle and joint interactions. In: kinesiology of the musculoskeltal system", 2nd ed., Philadelpia: Mosby, 2010.

[22] Lee H.J., Leslie L.N., Roger D.A., Chris G.M., Mark H., Bae S.S., "Development and Psychometric Testing of Korea Language Versions of 4 Neck Pain and Disability Questionnaires", Spine, Vol. 31, No. 16, pp. 1841-1845, 2006.

[23] Kim MJ, Cho WJ, Kang SY, Lee WS, Park JW, "Evaluation of clinical availability for shoulder forced traction method to minimize the beam hardening artifact in Cervical- spine Computed Tomography(CT)", JKSR, Vol. 7, No. 1, pp. 37-44, 2013.

[24] Cote P., Cassidy J.D., Carroll L., "The Prevalence of neck pain and related disability in Saskatchewan adults", Spine, Vol. 23, pp. 1689-1698, 1998,

[25] Kim Y.M., "Effects of the Use of the Hold Relax Technique to Treat Female VDT Workers with Work-related Neck-shoulder Complaints", KSOEM, Vol. 21, No.1, pp. 18-27, 2009.
[26] Bae S.S., Kim B.J., Lee G.H., "A Study of Muscle Imbalance of Head, Cervical and Shoulder Region", KSPT, Vol. 13, No, 3, pp. 769-776, 2001.

[27] Bronfort G., Evans R., Nelson B. "Manipulation for patients with chronic neck pain: Arandomized clinical trial of exercise and spinal", Spine, 2001, Vol. 26, pp. 788-799.

[28] Jung Y.W., Yoon S.W., Lee J.W., "The Effects of Therapeutic Exercise on the Grip Strength of Chronic Neck Pain Patients", KSPM, Vol. 4, No. 2, pp. 73-78, 2009.

[29] Choi SJ, Choi WS, Moon OK, “ A Study on the Load Analysis of Gliding Grade under the Kaltenborn-Evjenth ConceptR,; JKSR, Vol. 6, No. 5, pp. 383-388, 2012.

[30] Kyhlback M., Thierfelder T., Soulerlund A., "Prognostic factors in whiplash-associated disorders", IJRR, Vol. 25, No. 3, pp. 181-187, 2002.

[31] Jung J.Y., Jin Y.S., Kim H.S., Park E.Y., Kim H.K., Park E.K., "The effect of 8 weeks home-exercise program on VAS, NDI, ROM, cervical spine curvature in chronic neck pain patients", KAHPERD, Vol. 46, No. 4, pp. 437-445, 2007. 